OPEN ACCESS

Edited by:

Xenia Gonda,

Semmelweis University, Hungary

Reviewed by:

Neven Henigsberg,

University of Zagreb, Croatia

Yasuhiro Kaneda,

Iwaki Clinic, Japan

*Correspondence:

Agorastos Agorastos aagorast@auth.gr

${ }^{\dagger}$ These authors have contributed equally to this work

Specialty section:

This article was submitted to Mood and Anxiety Disorders,

a section of the journal

Frontiers in Psychiatry

Received: 12 March 2020

Accepted: 05 May 2020

Published: 20 May 2020

Citation:

Agorastos A, Sommer A, Heinig A Wiedemann K and Demiralay C (2020)

Vasopressin Surrogate Marker

Copeptin as a Potential Novel

Endocrine Biomarker for

Antidepressant Treatment Response

in Major Depression: A Pilot Study.

Front. Psychiatry 11:453.

doi: 10.3389/fpsyt.2020.00453

\section{Vasopressin Surrogate Marker Copeptin as a Potential Novel Endocrine Biomarker for Antidepressant Treatment Response in Major Depression: A Pilot Study}

\author{
Agorastos Agorastos $^{1,2,3 * \dagger}$, Anne Sommer ${ }^{1 \dagger}$, Alexandra Heinig ${ }^{1}$, Klaus Wiedemann ${ }^{1}$ \\ and Cüneyt Demiralay ${ }^{1}$ \\ 1 Department of Psychiatry and Psychotherapy, University Medical Center Hamburg-Eppendorf, Hamburg, Germany, \\ ${ }^{2}$ Department of Psychiatry, Division of Neurosciences, Faculty of Health Sciences, School of Medicine, Aristotle University of \\ Thessaloniki, Thessaloniki, Greece, ${ }^{3}$ VA Center of Excellence for Stress and Mental Health (CESAMH), VA San Diego \\ Healthcare System, San Diego, CA, United States
}

Background: Major depressive disorder (MDD) constitutes the leading cause of disability worldwide. Although efficacious antidepressant pharmacotherapies exist for MDD, only about $40-60 \%$ of the patients respond to initial treatment. However, there is still a lack of robustly established and applicable biomarkers for antidepressant response in everyday clinical practice.

Objective: This study targets the assessment of the vasopressin (AVP) surrogate marker Copeptin (CoP), as a potential peripheral hypothalamic-level biomarker of antidepressant treatment response in MDD.

Methods: We measured baseline and dynamic levels of plasma CoP along with plasma ACTH and cortisol (CORT) in drug-naive outpatients with MDD before and after overnight manipulation of the hypothalamic-pituitary-adrenal (HPA) axis [i.e., stimulation (metyrapone) and suppression (dexamethasone)] on three consecutive days and their association with treatment response to 4 weeks of escitalopram treatment.

Results: Our findings suggest significantly higher baseline and post-metyrapone plasma CoP levels in future non-responders, a statistically significant invert association between baseline CoP levels and probability of treatment response and a potential baseline plasma CoP cut-off level of above $2.9 \mathrm{pmol} / \mathrm{L}$ for future non-response screening. Baseline and dynamic plasma ACTH and CORT levels showed no association with treatment response.

Conclusions: This pilot study provide first evidence in humans that CoP may represent a novel, clinically easily applicable, endocrine biomarker of antidepressant response, based on a single-measurement, cut-off level. These findings, underline the role of the vasopressinergic system in the pathophysiology of MDD and may represent a 
significant new tool in the clinical and biological phenotyping of MDD enhancing individualtailored therapies.

Keywords: copeptin, vasopressin (AVP), depression, hypothalamus-pituitary-adrenal axis (HPA axis), cortisol, biomarker, treatment response, antidepressants

\section{INTRODUCTION}

Major depressive disorder (MDD) is a debilitating disease of high lifetime prevalence and constitutes worldwide the leading cause of disability due to chronic disease burden as it is significantly associated with a broad range of physical co-morbidities and higher overall mortality (1-3). Despite some controversial debates (4), pharmacotherapy with antidepressant agents is considered one of the best-established, efficacious, and widely used first-line treatments for MDD (5). Nevertheless, only about $40-60 \%$ of the patients respond to initial antidepressant therapy, while only approximately a third will reach remission and about 30-40\% may experience treatment resistance even when receiving optimal antidepressant treatment according to consensus guidelines (6-8). Medication switch and augmentation strategies are then often employed, however with decreasing effectiveness at each successive treatment step $(7,9)$. As poor response is associated with higher functional impairment, mortality, morbidity, and chronicity of the disorder in the long term $(10,11)$, the identification of robust and generally applicable predictive factors of antidepressant nonresponse is highly warranted. However, besides some general negative clinical and psychosocial predictors of non-response (12), there is a lack of objective, individualized, and applicable biomarkers able to distinguish pathophysiological subgroups of depressed patients with different response to antidepressant treatment in everyday clinical practice (13).

Pathophysiologically, MDD is considered a stress-related disorder with distinct neuroendocrine profile (14), in particular showing alterations in the physiological function of the hypothalamic-pituitary-adrenal (HPA) neuroendocrine axis (2, 15). Hereby, HPA axis hyperactivity with higher cortisol (CORT) levels, increased corticotropine releasing hormone $(\mathrm{CRH})$, and adrenocortocotropic hormone (ACTH) activity, attenuated CORT awakening response and altered feedback-circuits with reduced glucocorticoid receptor sensitivity are among the most consistent and robust findings (2, 15-20). In addition, antidepressant treatment leading to remission of the depressive psychopathology has been shown to be associated to normalization of the altered neuroendocrine stress system regulation (20-22). HPA axis functioning has been, accordingly, extensively studied using neuroendocrine challenge tests that attenuate or enhance CORT, ACTH, and $\mathrm{CRH}$ release (i.e., HPA axis suppression or stimulation) in terms of their potential predictive validity with respect to antidepressant response, as a subgroup of MDD patients with HPA axis alterations may be less likely to respond to treatment with antidepressants. Unfortunately, to date, and despite initial enthusiasm of pioneer studies (23), most results could not be adequately replicated and no pre-treatment basal or dynamic peripheral endocrine measure [i.e., baseline CORT, ACTH, $\mathrm{CRH}$, assessment of the vasopressin (AVP), CORT/ dehydroepiandrosterone ratio, dexamethasone (DEX) suppression test (DST), DEX/CRH test] was able to be robustly established as a valid and clinically applicable biomarker for antidepressant response (24-28).

However, the valid assessment of the hypothalamic level of the HPA axis functioning is challenging. The co-secreted and synergistically at this level acting CRH and AVP cannot be simply measured because of their pulsatile secretion pattern, small molecular size, avid binding to platelets, rapid plasma clearance, degradation, and instability $(28,29)$. In contrast, a surrogate marker of AVP secretion, the 39-amino-acid glycopeptide copeptin $(\mathrm{CoP})$, is a more stable molecule in the circulation even at room temperature (ex vivo) and can be easily and reliably measured with a sandwich immunoassay $(30,31)$. CoP is the C-terminal cleavage part of the precursor pre-proAVP and is co-released in an equimolar ratio to AVP, thus closely mirroring AVP secretion, without a specific physiological function of its own (i.e., analogous to C-peptide for insulin) $(32,33)$. CoP has therefore emerged as a promising biomarker in several AVP-associated endocrine, cardiovascular, pulmonary, and renal disorders, as well as other acute medical stress states (e.g., sepsis) (30, 34-38).

However, to date, CoP has with few exceptions (39) not been regularly investigated in psychiatric research and, to date, no study has particularly assessed $\mathrm{CoP}$ as a treatment response biomarker in MDD. Thus, the main objective of our study was to assess $\mathrm{CoP}$ as a potential hypothalamic biomarker of antidepressant treatment response in MDD patients in order to investigate its predictive properties distinguishing responders from non-responders. Based on previous studies on HPA axis (re)activity $(24,26)$, we hypothesized that hyperactivity of the axis (i.e., vasopressinergic hyperdrive) with higher CoP plasma levels would be associated with poorer response to antidepressant treatment (40).

\section{MATERIALS AND METHODS}

\section{Study Participants and Inclusion Criteria}

The study was approved by the ethics review committee (ERC) of the Hamburg Medical Board (file Nr. PV4161). Patients were recruited through our specialized depression outpatient clinic at the Department of Psychiatry and Psychotherapy, University Medical Center Hamburg-Eppendorf. After full oral and written explanation of the purpose and procedures of the investigation, written informed consent was obtained from each patient before initiating the screening procedure and enrollment in the study. Screening included a thorough physical and neurological examination, routine blood laboratory tests, urine toxicology 
screen, electrocardiogram (ECG), and a structured face-to-face clinical interview. Inclusion criteria included age of 18-65 years, a psychiatrist-confirmed diagnosis of non-psychotic MDD, single or recurrent, according to Diagnostic and Statistical Manual of Mental Disorders IV - Text Revision (DSM-IV-TR) criteria and an additional confirmatory minimum cut-off score for at least moderate depression on both the clinician- and selfrated Inventory of Depressive Symptomatology (IDS) questionnaire, as well as at least 8 weeks free of any psychiatric medication. Exclusion criteria included presence or self-reported history of any chronic or acute physical and axis I mental comorbidities, history of psychotic MDD, body mass index (BMI) values beyond $18-30 \mathrm{~kg} / \mathrm{m}^{2}$, frequent usage of any either illicit or prescribed drugs or over the counter medications, drinking of more than $100 \mathrm{~g}$ of alcohol per week, current adverse life events (e.g., divorce, loss of job, and illness in the family), night shifts or transcontinental flights across more than four time zones during the past 4 weeks, abnormal physical and neurological examinations, basic blood laboratory test values deviating from the normal range, positive urine toxicology screen, actual menstruation, pregnancy, nursing, or not using a reliable method of birth control, any contraindication for DEX or metyrapone, and pathological initial ECG. Hypothyroidism in the euthyroid state through hormonal substitution, as well as hypertension in normotensive state through antihypertensive medication, did not serve as exclusion criteria. Smoking status (smoking 1 cigarette/cigar/pipe or chewing tobacco $1 \mathrm{x} /$ day or more) has been assessed by self-report as a dichotomous variable (yes/no). We enrolled antidepressant-free patients with a clinical, non-psychotic MDD and without other physical and psychiatric comorbidities.

\section{Study Procedures}

Patients who met study inclusion and exclusion criteria were scheduled for study initiation within 1 week of final laboratory results. The study assessed endocrine plasma levels of CORT, $\mathrm{ACTH}$, and CoP at the morning of three consecutive days (same week-days for all patients: Monday-Wednesday) to measure HPA-axis activity after two endocrine challenges described below (challenge 1: Overnight Metyrapone Stimulation Test, MST; challenge 2: Overnight Low-Dose DST): day 1 (baseline), day 2 (post-MET), and day 3 (post-DEX). All subjects were encouraged to maintain a regular sleep time starting at around 11.00 p.m. for all three nights before study days $1-3$, with wakeup at 7.00 a.m. and avoidance of physical strain (e.g. physical exercise, sexual activity, etc.) on all three study mornings. Furthermore, participants were encouraged to use public transportation or private motor vehicles [i.e. no bicycles or walking $>500 \mathrm{~m}$ to exclude to potential effects of elevated physical activity on heart rate (HR) measures] to reach the study facility and to avoid any intake of food or beverages (water was allowed) until completion of the assessment. After reaching the study facility (at 8.30 a.m.), all patients were given $15 \mathrm{~min}$ in sitting and $15 \mathrm{~min}$ in supine position in a single bedded room before the blood draw (09.00 a.m. of each study day).

Immediately after day 3 assessment, antidepressant pharmacotherapy with escitalopram (ESC) was initiated in all patients. ESC was selected as antidepressant agent of choice according to several international guidelines recommending selective serotonin reuptake inhibitors (SSRIs) as first-line treatment for depression (41-43) and some guidelines and meta-analyses noting possible superiority of escitalopram over other SSRIs with respect to efficacy, safety, tolerability, and cost (5, 41-43). Antidepressant treatment with ESC was initiated with an initial titration dosage scheme of $5 \mathrm{mg} / \mathrm{d}$ for $5 \mathrm{~d}$ and subsequent elevation and maintenance antidepressant treatment of 10-20 mg/ $\mathrm{d}$ each morning. Treatment response was evaluated after a total of 4 weeks of maintenance treatment (i.e., total $32 \mathrm{~d}$ from starting date) through detailed clinical assessment including questionnaire evaluation as described below. Response to antidepressant treatment was defined as a reduction of $50 \%$ or more on both the initial $\mathrm{IDS}_{30}-\mathrm{C}$ and $\mathrm{IDS}_{30}$-SR depression scores.

\section{Endocrine Challenges}

- Overnight Metyrapone Stimulation Test (MST): The MST test is considered to be a simple and sensitive alternative test to evaluate the ACTH reserve and is useful to evaluate the response of the HPA axis $(44,45)$. MET crosses the blood-brain barrier and reduces, not only at the adrenal glands but also within the brain, CORT levels by blocking the enzymatic conversion of 11-deoxyCORT to CORT by CYP11B1 (11-beta-hydroxylase, P-450c11), the last step in the synthesis of CORT. This leads to a rapid fall of CORT and an accumulation of 11-deoxy-CORT, which does not inhibit ACTH secretion. This results in decreased CORTmediated negative feedback at hypothalamic and pituitary levels, which increases $\mathrm{CRH}$ and ACTH secretion. Subjects received $1 \mathrm{~g}$ of MET (Metopiron ${ }^{\circledR}$, Novartis, Arnhem, Netherlands) orally at 11.00 p.m. on day 1, to assess its effects on endocrine measures the next morning (day 2, approx. $9 \mathrm{~h}$ after metyrapone intake).

- Overnight Low-Dose Dexamethasone Suppression Test (DST): The low-dose DST is one of the commonly used tests to assess HPA axis reactivity by measuring the change in peripheral CORT levels in response to externally administered DEX (46). DEX is an exogenous steroid that binds mainly to glucocorticoid receptors in the anterior pituitary gland. This results in regulatory modulation through negative feedback and suppression of ACTH and consequently lowers CORT secretion (47). Subjects received $1 \mathrm{mg}$ of DEX (Fortecortin ${ }^{\circledR}$, Merck, Darmstadt, Germany) orally at 11.00 p.m. on day 2, to assess its effects on endocrine measures the next morning (day 3, approx. $9 \mathrm{~h}$ after DEX intake).

The temporal order of the two endocrine challenges was chosen to avoid any interference between the two interventions, as half-life times significantly differ between metyrapone (approx. $2 \mathrm{~h}$ ) and DEX (35-54 h). Subjects were blinded with respect to the specific order of endocrine challenges.

\section{Laboratory Assays}

Blood samples were obtained in EDTA coated tubes at 09.00 a.m. of each study day. Blood was placed in ice, plasma was separated and stored at $-80^{\circ} \mathrm{C}$ until analysis. We determined CORT (CORT, ng/ml), adrenocorticotropic hormone (ACTH, pg/ml), and $\mathrm{CoP}$ (pmol/l) plasma levels using commercially available immunoradiometric assays and radio-immunoassays (DRG 
International Inc., USA; MP Biomedicals, Solon, USA; BRAHMS Kryptor, Berlin, Germany; respectively). The lower detection limit for CORT was $0.9 \mathrm{ng} / \mathrm{ml}$ and for ACTH was $5.7 \mathrm{pg} / \mathrm{ml}$. Intra- and inter-assay coefficients of variation (CVs) were below $8 \%$ for all assays.

\section{Measures}

All subjects underwent a detailed clinical assessment. Diagnosis of MDD, as well as exclusion of other current or lifetime comorbid axis I psychiatric disorders were established with the Structured Clinical Interview for the DSM-IV-TR Axis I Disorders (SCID-I) by experienced and specially-trained, board-certified psychiatrists. All other medical exclusion criteria were assessed in a clinical interview setting through study questionnaires. Depression severity was assessed using the German version of the IDS (48), a 30-item questionnaire with a clinical-rated (IDS ${ }_{30}-\mathrm{C}$ ) and self-rated version (IDS ${ }_{30}-\mathrm{SR}$ ), as it is proven to be more sensitive to changes in depressive psychopathology than other questionnaires (e.g., the Hamilton Depression Rating Scale) (49). The IDS is an assessment tool of excellent psychometric properties (total score range: $0-84$ ) (50) that can be used to screen or assess the severity of depression and is widely used in large national and international multicenter studies and clinical trials both in- and outpatients (51), providing detailed information on depressive symptoms through 30 equally-weighted-items, including all nine Diagnostic and Statistical Manual (DSM) domains. Both an $\mathrm{IDS}_{30}-\mathrm{C}$ initial score of 23/24 and IDS $_{30}$-SR initial score of 25/26 were used as cut-off scores, as indicated in prior literature (52), indicating clinical depression of at least moderate level and served as additional and confirmatory inclusion criterion to the study. Response to antidepressant treatment was defined as a reduction of $50 \%$ or more on both the initial $\mathrm{IDS}_{30}-\mathrm{C}$ and $\mathrm{IDS}_{30}$-SR depression scores. History of childhood maltreatment was assessed with the Childhood Trauma Questionnaire (CTQ) (53) and is presented as the total CTQ score (range: 25-125).
Sleep quality was measured using the Pittsburgh Sleep Quality Index (PSQI) (54) and is presented as the total PSQI score. Adverse side effects were assessed through a German version of the UKU side effects rating scale (55).

\section{Statistical Analyses}

Because several endocrine parameters showed skewed distribution, all endocrine parameters were ln-transformed for further parametric analysis. Preliminary analyses were performed to ensure no violation of the assumptions of normality, linearity and homoscedasticity. Ln-transformed parameters are presented as geometric means on the original scale through back-transformation through exponentiation of ln-transformed data. An error probability of $p<0.05$ was accepted as statistically significant. Effect size is reported as partial eta squared $\left({ }_{p} \eta^{2}=0.01\right.$ : small effect size, ${ }_{p} \eta^{2}=0.06$ : medium effect size, ${ }_{p} \eta^{2}=0.14$ : large effect size). To correct for potentially inflated type I error due to multiple comparisons we used the false discovery rate (FDR) approach (56), as in our previous studies (57-61). Following a previously reported procedure (62) $p$-values were corrected by the minimum positive FDR with a threshold set at 5\%. Statistical analyses were conducted using the Statistical Package for Social Sciences Version 20 (SPSS, Chicago, IL).

\section{RESULTS}

One hundred seventy-five depressed patients were screened. Sixty-one patients were found eligible for participation in the study. Of those, 42 declined participation at the time of the scheduling phone call, 4 did not attend at scheduled appointment and 1 dropped out due to mild gastrointestinal side effects on day 1 by MET. We collected and analyzed data from 14 Caucasian study completers with MDD. Sample characteristics and psychometric scores can be found at Table 1. None of the

TABLE 1 | Demographic, physical, and psychometric measures in MDD patients and group differences between responders and non-responders to ESC antidepressant treatment.

\begin{tabular}{|c|c|c|c|c|c|c|}
\hline \multirow[t]{2}{*}{ Value } & \multirow[t]{2}{*}{ Total Sample } & \multirow{2}{*}{$\begin{array}{c}\text { Responders } \\
\text { N (\%) }\end{array}$} & \multirow[t]{2}{*}{ Non-Responders } & \multicolumn{3}{|c|}{ Responders vs. Non-Responders } \\
\hline & & & & & & $p$ \\
\hline Participants & 14 (100.0\%) & $8(57.1 \%)$ & $6(42.9 \%)$ & & & \\
\hline Males & 5 (35.7\%) & $2(25.0 \%)$ & $3(50.0 \%)$ & & & .580 \\
\hline Smokers & $5(35.7 \%)$ & $3(37.5 \%)$ & $2(33.3 \%)$ & & & .999 \\
\hline \multirow[t]{2}{*}{ History of depression } & $8(57.1 \%)$ & $5(62.5 \%)$ & $3(50.0 \%)$ & & & .957 \\
\hline & & Mean (SEM) & & $F$ & $t$ & $p$ \\
\hline Age & $36.9(2.3)$ & $38.6(2.3)$ & $34.5(4.5)$ & 2.382 & -.881 & .396 \\
\hline BMI & $26.1(1.6)$ & $24.5(1.9)$ & $28.2(2.7)$ & .326 & 1.172 & .264 \\
\hline PSQI & $11.9(1.1)$ & $11.7(1.4)$ & $12.2(2.0)$ & 1.310 & .190 & .853 \\
\hline CTQ & $41.4(2.4)$ & $41.5(2.4)$ & $41.2(4.9)$ & .846 & -.067 & .948 \\
\hline IDS-SR Baseline & $44.8(2.0)$ & $44.1(2.7)$ & $45.7(3.2)$ & .492 & .369 & .719 \\
\hline IDS-C Baseline & $42.8(2.1)$ & $42.4(2.1)$ & $43.2(4.0)$ & .427 & .171 & .867 \\
\hline IDS-SR Post-Treatment & $26.3(3.0)$ & $18.2(2.6)$ & $37.0(1.7)$ & 1.024 & 5.598 & $<.001^{\star \star \star}$ \\
\hline IDS-C Post-Treatment & $20.6(2.9)$ & $13.5(2.5)$ & $30.0(3.0)$ & .033 & 4.257 & $.001^{\star \star}$ \\
\hline
\end{tabular}

Values are presented as total numbers (percent of total) and means (SEM). Psychometric scores report total scores. Age is reported in years. BMI, body mass index (kg/m²); PSQl, Pittsburgh Sleep Quality Index; CTQ, Childhood Trauma Questionnaire; IDS-SR, Inventory of Depressive Symptomatology-Self Report; IDS-C, IDS-Clinician. Group differences were assessed through t-test (parametric) or chi-squared test (nominal). Significant results are bolded. FDR analysis revealed no potential type I errors. ${ }^{* *} p<0.01$; ${ }^{* * *} p<0.001$. 
subjects of the final sample was receiving additional medication (i.e. antihypertensive medication or thyroid hormone substitution). Side effects as per UKU ratings did not differ significantly between days indicating no significant adverse effects (data not shown). Of the 14 study completers, eight (57.1\%) showed a treatment response after 4 weeks of ESC antidepressant treatment. The responder group did not differ from the non-responder group with respect to age, BMI, and initial depression, childhood trauma exposure, and sleep scores, nor did they differ in gender distribution, smoking status, and history of previous depression (Table 1). Mean ESC dosage was 17.1 (1.0; range: $10-20) \mathrm{mg} / \mathrm{d}$ in the total sample and did not differ significantly between the two groups [responders: $16.9(1.3)$ $\mathrm{mg} / \mathrm{d}$; non-responders: $\left.17.5(1.7) \mathrm{mg} / \mathrm{d} ; t_{(12)}=.295, p=.773\right)$

Adjusted geometrical means (SEM) of CORT, ACTH, and CoP levels across days 1-3 are presented at Figure 1 and Table 2. There were no statistically significant differences with respect to
CORT, ACTH, and CoP levels across days 1-3 with respect to gender, smoking status, medication dosage received, or history of previous depression (data not shown). There were also no statistically significant correlations between baseline CORT, $\mathrm{ACTH}$, and CoP levels and psychometric scores, or their changes $(\Delta)$ through antidepressant treatment (data not shown).

A mixed between-within subject ANOVA was conducted to assess the difference between responders and non-responders on CORT, ACTH, and CoP levels across days 1-3. Results indicated a highly significant effect of time (i.e. treatment condition) in all three measures with very large effect sizes, which confirmed the expected effects of each treatment condition (CORT: Wilk's lamda $=.015, \mathrm{~F}_{(2,11)}=368.625, \mathrm{p}<.001,{ }_{p} \eta^{2}=.985 ;$ ACTH: Wilk's lamda $=.061, \mathrm{~F}_{(2,11)}=85.189, \mathrm{p}<.001,{ }_{p} \eta^{2}=.939 ; \mathrm{CoP}:$ Wilk's lamda $\left.=.544, \mathrm{~F}_{(2,11)}=4.616, \mathrm{p}=.035,{ }_{p} \eta^{2}=.456\right)$. For CORT and ACTH, group (i.e., response vs. non-response) had no significant effect (CORT: $\mathrm{F}=.278, \mathrm{p}=.608,{ }_{p} \eta^{2}=.023 ;$ ACTH:
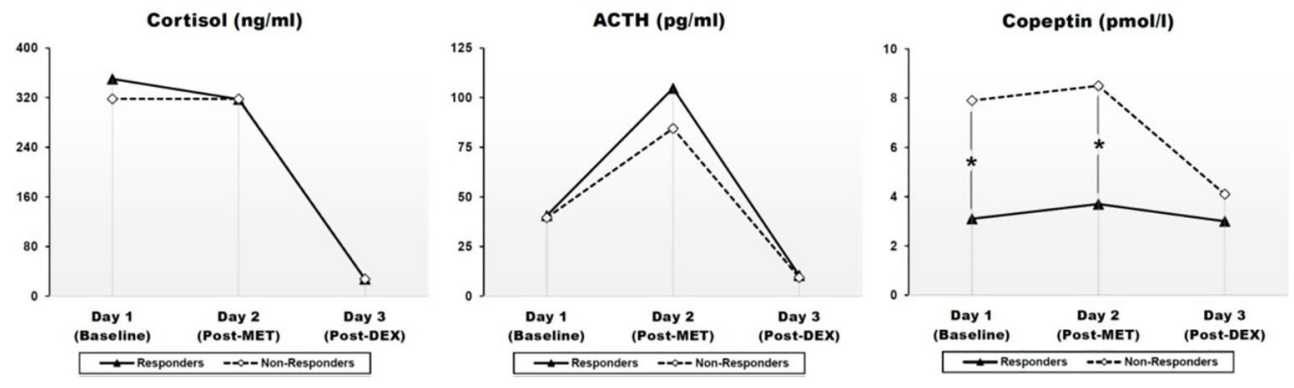

FIGURE 1 | Effects of metyrapone (MET) and dexamethasone (DEX) on cortisol (CORT), ACTH, and CoP in responders and non-responders to ESC antidepressant treatment. Graphic presentation of Table 2. Pointwise values represent geometrical means adjusted for age, gender, BMl, history of previous depression and smoking. Group differences were assessed through a linear analysis of covariance (ANCOVA), controlling for age, gender, BMl, history of previous depression, and smoking. ACTH: Adrenocorticotropic hormone. Day 1: baseline; day 2: Post-MET: post-metyrapone; day 3: post-DEX: post-dexamethasone. A mixed betweenwithin subject ANOVA indicated a highly significant effect of time (i.e. treatment condition) in all three measures with very large effect sizes, which confirmed the expected effects of each treatment condition (cf. Results section). Group (response vs. non-response) had a significant effect only for CoP, but not for CORT or $\mathrm{ACTH}$, suggesting a statistically significant difference between responders and non-responders on CoP levels across days $1-3$ (cf. Results section). ${ }^{\star} p<0.05$.

TABLE 2 | Adjusted geometric means of endocrine measures across the three conditions and group differences between responder and non-responder to escitalopram (ESC) antidepressant treatment.

\begin{tabular}{|c|c|c|c|c|c|c|}
\hline \multirow[t]{2}{*}{ Value } & \multirow[t]{2}{*}{ Day } & \multicolumn{2}{|c|}{$\begin{array}{l}\text { Adjusted Geometrical } \\
\text { Means (SEM) }\end{array}$} & \multicolumn{3}{|c|}{$\begin{array}{l}\text { Controlled group differences } \\
\text { (ANCOVA) }\end{array}$} \\
\hline & & Responders & Non-Responders & $\boldsymbol{F}$ & $p$ & ${ }_{p} \eta^{2}$ \\
\hline \multirow[t]{3}{*}{ CORT } & Day 1: baseline & $350.0(1.1)$ & $318.0(1.2)$ & .226 & .651 & .036 \\
\hline & Day 2: post-MET & $317.3(1.1)$ & $317.7(1.1)$ & .000 & .998 & .000 \\
\hline & Day 3: post-DEX & $27.5(1.1)$ & $27.7(1.2)$ & .001 & .978 & .000 \\
\hline \multirow[t]{3}{*}{ АCTH } & Day 1: baseline & $40.6(1.2)$ & $39.5(1.3)$ & .006 & .940 & .001 \\
\hline & Day 2: post-MET & $104.7(1.2)$ & $84.5(1.3)$ & .373 & .564 & .059 \\
\hline & Day 3: post-DEX & $10.4(1.1)$ & $9.4(1.1)$ & .527 & .495 & $.081^{+}$ \\
\hline \multirow[t]{3}{*}{ CoP } & Day 1: baseline & $3.1(1.2)$ & $7.9(1.2)$ & 12.913 & $.011^{*}$ & $.683^{++}$ \\
\hline & Day 2: post-MET & $3.7(1.2)$ & $8.5(1.2)$ & 8.154 & $.029^{\star}$ & $.576^{++}$ \\
\hline & Day 3: post-DEX & $3.0(1.3)$ & $4.1(1.3)$ & .778 & .412 & $.115^{+}$ \\
\hline
\end{tabular}

Values are presented as geometric mean values (SEM) adjusted for age, gender, history of previous depression, BMI and smoking. Group differences were assessed through a linear ANCOVA, controlling for age, gender, BMI, history of previous depression, and smoking. ACTH: Adrenocorticotropic hormone. Day 1: baseline; day 2: Post-MET: post-metyrapone; day 3: post-DEX: post-dexamethasone. Significant results are bolded. FDR analysis revealed no potential type I errors. ANCOVA, analysis of variance; CoP, copeptin; CORT, cortisol; DEX, dexamethasone; MET, metyrapone. ${ }^{+}$medium effect size, ${ }^{++}=0.14$ : large effect size. ${ }^{*} p<0.05$. 
$\mathrm{F}=.271, \mathrm{p}=.612,{ }_{p} \eta^{2}=.022$ ), nor was there any statistically significant group $x$ time interaction (data not shown), suggesting no difference between responders and non-responders regarding CORT and ACTH levels across days 1-3. In contrast, for CoP, group had a significant effect on CoP levels across day $1-3(\mathrm{~F}=$ 9.992, $\left.\mathrm{p}=.008,{ }_{p} \eta^{2}=.454\right)$, although lacking significant group $x$ time interaction (Wilk's lamda $=.908, \mathrm{~F}_{(2,11)}=.560, \mathrm{p}=.587$, $\left.{ }_{p} \eta^{2}=.092\right)$, suggesting a statistically significant difference between responders and non-responders on $\mathrm{CoP}$ levels across days $1-3$.

A logistic regression was performed to ascertain the effects of baseline plasma CoP levels on the likelihood of response to antidepressant treatment. The logistic regression model was statistically significant $\left(\chi_{(1)}^{2}=7.784, p=.005\right)$. The model explained $57.3 \%$ (Nagelkerke $R 2$ ) of the variance in treatment response and correctly classified $85.7 \%$ of cases. Higher baseline plasma CoP levels were significantly associated with a decreased likelihood of antidepressant treatment response $(B=-.599, S E=$ .277, Wald $=4.226, d f=1, p=.040, O R=.572,95 \% C I$ for OR:.336-.974). Every increase of baseline plasma CoP level of 1.0 $\mathrm{pmol} / \mathrm{L}$ almost doubled the possibility of non-response. The relation between treatment response and plasma CoP levels was also examined using receiver operating characteristic (ROC) curves. The area under the curve was.823, which indicates that baseline plasma CoP levels are quite accurate in identifying response to antidepressant treatment. The ROC diagram suggested a plasma CoP cut-off level of $2.9 \mathrm{pmol} / \mathrm{L}$ (sensitivity $87.5 \%$, specificity $83.3 \%$ ) as the most appropriate one for screening purposes of non-response. A direct univariate logistic regression $\left(\chi_{(1)}^{2}=5.004, p=.025\right.$, Nagelkerke $\left.R 2=40.3 \%\right)$, which correctly classified $78.6 \%$ of cases, indicated that depressed patients with a plasma CoP level above $2.9 \mathrm{pmol} / \mathrm{L}$ had a significantly higher probability of non-response $(B=-2.708$, $S E=1.366$, Wald $=3.929, d f=1$, Sig. $=.047, \mathrm{OR}=.067,95 \% C I$ for OR:.005-.970, FDR analysis indicated a potential type I error).

\section{DISCUSSION}

The main objective of our study was to assess the AVP surrogate marker $\mathrm{CoP}$ as a potential peripheral hypothalamic biomarker of treatment response in MDD patients and to investigate its predictive properties distinguishing responders from nonresponders to standardized antidepressant treatment with ESC. We measured plasma CoP in MDD patients before and after manipulation of the HPA axis [i.e., stimulation (MET) and suppression (DEX)], along with plasma ACTH and CORT, in order to assess baseline and dynamic changes in all three levels of the axis and their correlation. To the best of our knowledge, this is the first study investigating plasma $\mathrm{CoP}$ as an endocrine predictor of antidepressant treatment in MDD. The main findings of the study include i) a significant difference between responders and non-responders between baseline and post-MET CoP levels, while no difference was apparent with respect to $\mathrm{ACTH}$ and CORT, ii) a statistically significant association between higher baseline plasma CoP levels and lower probability of treatment response, and iii) a baseline plasma CoP cut-off level above $2.9 \mathrm{pmol} / \mathrm{L}$ with a potential screening applicability in the differentiation between responder and non-responder.

Given that AVP is not considered a valid biomarker in MDD and psychiatric disorders in general (28), our results offer first evidence that plasma CoP may represent an alternative stable, easily accessible, and clinically applicable peripheral biomarker of antidepressant treatment response in MDD. CoP has been lately put forth as a possible novel stress marker as some studies have reported $\mathrm{CoP}$ to subtly mirror the individual stress level in psychological (63-65) and physical stress paradigms (66), while CoP has shown a positive correlation with other HPA axis hormones $(64,67-70)$. In a previous study of our research group (39), we could show that, following an objective, pharmacological panic challenge, plasma CoP not only delicately responded through a sharp increase to panic provocation and positively correlated with simultaneously assessed ACTH and CORT, but also significantly correlated with subjectively reported panic symptoms, which was not the case for ACTH and CORT. Our study found no correlation between CoP and ACTH and CORT, similarly to previous studies in $\mathrm{MDD}$ patients $(67,71)$. Taken together, this suggests that CoP can be reliably used as surrogate marker of AVP secretion and may even better represent the hypothalamic level of the HPA axis in stress-related disorders and MDD than CRH and AVP itself.

Our results are in accordance to the close association of the vasopressinergic system with HPA axis (re)activity and support a central role of the AVP neural system in the coordination of neuroendocrine responses to stress in the pathophysiology of MDD (40, 72-76). AVP modulates the release of ACTH and potentiates the effects of $\mathrm{CRH}$ on the pituitary, mainly through the $\mathrm{G}$-protein-coupled vasopressin $1 \mathrm{~b}\left(\mathrm{~V}_{1 \mathrm{~b}}\right)$ receptor and its expression $(40,74)$, while it is important to note that $V_{1 b}$ receptors have been additionally detected in the septum, cortex and hippocampus (77-79). Interestingly, AVP effects on HPA axis seem to differ between acute and chronic stress (80). Prolonged stress up-regulates AVP and pituitary $\mathrm{V}_{1 \mathrm{~b}}$ expression $(74,81,82)$, possibly through an impairment in the repression of the AVP promoter (83). Polymorphisms in the promoter structures of the AVP gene and $V_{1 b}$ receptor genes, could thus contribute to individual variation in stress resilience but also phenotypic expression of stress-related disorders and represent a promising target for pharmacotherapeutic interventions (75).

In $\mathrm{MDD}$, an increased number of AVP-expressing neurons and increased AVP mRNA expression has been reported in the hypothalamic Periventricular Nucleus (PVN) (84, 85), along with elevated AVP plasma levels (86-90), confirming vasopressinergic hyperactivity with pituitary but also extrahypothalamic and extra-pituitary AVP neuropeptidergic hyperdrive $(40,91)$. This AVP overdrive can lead to a "switch" in the regulation of the HPA system from CRH to AVP control, resulting in an altered homeostasis within the HPA system with different neurobiological, behavioral, and emotional effects (82) as seen in MDD $(91,92)$. Indeed, MDD is characterized by increased HPA responsiveness to AVP and decreased 
responsiveness to $\mathrm{CRH}$ (82), while antidepressant action is shown to be related to reduction of vasopressinergic overexpression in these patients $(40,93)$. In addition, higher AVP plasma levels in MDD have been associated with distinct depression features, such as melancholic symptoms and psychomotor retardation during the day $(86,90,94)$. This is in accordance to our findings of higher CoP plasma levels in MDD patients showing future non-response in their clinical course, suggesting an association of a vasopressinergic hyperdrive with HPA axis-related, particularly burdening symptoms and negative outcome in MDD (76). It is, thus, not surprising that $\mathrm{V}_{1 \mathrm{~b}}$ receptor antagonists, inhibiting AVP and $\mathrm{CRH}$-induced ACTH release, have raised experimental interest as potential agents for the treatment of stress-related disorders and MDD (95). First clinical trials have supported anxiolytic- and antidepressant-like effects of such agents (e.g., SSR149415) in various animal-model and human clinical studies (96-100) and suggest that the $\mathrm{V}_{1 \mathrm{~b}}$ receptor is required to drive the HPA axis response to acute antidepressant treatment $(40,101)$.

Finally, some limitations of our study merit discussion. The most important limitation is the number of patients included in the study. Because of rigid exclusion criteria, the combined endocrine challenge and its time-consuming nature, our study investigated only a relatively small number of MDD patients. Thus, our findings should be considered preliminary and should be replicated in larger study populations. Because of the limited patient sample, the design of the study included the use of only one specific antidepressant, in order not to introduce additional confounders. On the other hand, all subjects were extremely carefully selected to minimize the probability of medical (e.g., medication use, systemic and chronic diseases, inflammatory states, deviating laboratory, or physical tests) and behavioral (e.g., substance and alcohol use) confounders. We particularly accounted for several laboratory markers (e.g., fasting glucose, hemoglobin A1c levels, cholesterol/ lipoproteins, pro-inflammatory cytokines, acute-phase proteins), subjective sleep problems, history of childhood trauma, BMI, gender, and other certain lifestyle habits (e.g., drug, alcohol or tobacco intake) that have been shown to be associated with alterations of the HPA axis (re)activity. Furthermore, our MDD patient sample reported similar depression scores as in reference studies (102), while their baseline morning CORT plasma levels were comparable to our prior studies on MDD patients (103-105), as was $\mathrm{CoP}$ (71), suggesting that we included a representative sample of MDD patients.

Secondary analyses investigating the impact of peri- and postmenopausal status (1 and 2 women, respectively) on our results, did not alter our findings (data not shown). However, although having excluded actual menstruation, we have not controlled for the specific menstrual phase of women participants. Additionally, it is very important to note that this study is measuring differences at defined time points of the day (i.e. single-time point measurements), which may relativize our findings. On the other hand, we assessed all individuals on three consecutive days, at the exact same time of day and the same week-days to minimize confounders. Finally, we acknowledge that nocturnal HPA axis stimulation/suppression leads to mainly indirect effects $9 \mathrm{~h}$ later. The complex pharmacokinetics of DEX and MET and their yet not fully understood interrelated pharmacodynamics, in addition to the nocturnal circadian phase with evolving different sleep stages and huge changes of HPA axis activity and circadian gene expression, represent important limitations with respect to the dynamic findings of this study.

\section{CONCLUSIONS}

Better clinical and biological phenotyping of MDD through novel biomarkers could improve the identification of MDD subtypes with respect to antidepressant treatment response and help routine patient stratification for individual-tailored therapies, which could improve response rates and shorten disease duration (106). To date, no specific biomarker has managed to establish clinical relevance in routine clinical practice. Our findings provide first evidence in humans that the AVP surrogate marker CoP might represent a novel, easily accessible and clinically applicable biomarker of excellent predictive properties, which can correctly identify treatment response in MDD patients through a single measurement based on a cut-off level. These findings, if replicated, might help establish a significant new clinical tool in the management of MDD and underline the role of the vasopressinergic system in the pathophysiology of MDD and treatment non-response.

\section{DATA AVAILABILITY STATEMENT}

The datasets generated for this study are available on request to the corresponding author.

\section{ETHICS STATEMENT}

The studies involving human participants were reviewed and approved by ethics review committee (ERC) of the Hamburg Medical Board (file Nr. PV4161). The patients/participants provided their written informed consent to participate in this study.

\section{AUTHOR CONTRIBUTIONS}

$\mathrm{AA}, \mathrm{CD}$, and $\mathrm{KW}$ designed the study and wrote the protocol. AA, $\mathrm{AS}, \mathrm{AH}$, and $\mathrm{CD}$ collected the data. AS and AA managed recruitment and screening of patients, as well as all literature searches. AA, AS, $\mathrm{AH}$, and $\mathrm{CD}$ had access to the raw data. AA, $\mathrm{AS}$, and $\mathrm{AH}$ performed all data processing and analyses. AA performed all statistical analyses and interpretation. AA and AS wrote the first draft of the paper. KW and CD revised the draft for important intellectual content. All authors have contributed to, read and approved the final version of the manuscript. 


\section{REFERENCES}

1. Moussavi S, Chatterii S, Verdes E, Tandon A, Patel V, Ustun B. Depression, chronic diseases, and decrements in health: results from the World Health Surveys. Lancet (2007) 370(9590):851-8. doi: 10.1016/S0140-6736(07)61415-9

2. Otte C, Gold SM, Penninx BW, Pariante CM, Etkin A, Fava M, et al. Major depressive disorder. Nat Rev Dis Primers (2016) 2:16065. doi: 10.1038/ nrdp. 2016.65

3. Friedrich MJ. Depression Is the Leading Cause of Disability Around the World. JAMA (2017) 317(15):1517. doi: 10.1001/jama.2017.3826

4. Cuijpers P, Sijbrandij M, Koole SL, Andersson G, Beekman AT, Reynolds CF3rd. The efficacy of psychotherapy and pharmacotherapy in treating depressive and anxiety disorders: a meta-analysis of direct comparisons. World Psychiatry (2013) 12(2):137-48. doi: 10.1002/wps.20038

5. Cipriani A, Furukawa TA, Salanti G, Chaimani A, Atkinson LZ, Ogawa Y, et al. Comparative efficacy and acceptability of 21 antidepressant drugs for the acute treatment of adults with major depressive disorder: a systematic review and network meta-analysis. Lancet (2018) 391(10128):1357-66. doi: 10.1016/ S0140-6736(17)32802-7

6. Cleare A, Pariante CM, Young AH, Anderson IM, Christmas D, Cowen PJ, et al. Evidence-based guidelines for treating depressive disorders with antidepressants: A revision of the 2008 British Association for Psychopharmacology guidelines. J Psychopharmacol (2015) 29(5):459-525. doi: 10.1177/0269881115581093

7. Rush AJ, Trivedi MH, Wisniewski SR, Nierenberg AA, Stewart JW, Warden $\mathrm{D}$, et al. Acute and longer-term outcomes in depressed outpatients requiring one or several treatment steps: a STAR ${ }^{\star} \mathrm{D}$ report. Am J Psychiatry (2006) 163 (11):1905-17. doi: 10.1176/ajp.2006.163.11.1905

8. Fava M, Davidson KG. Definition and epidemiology of treatment-resistant depression. Psychiatr Clin North Am (1996) 19(2):179-200. doi: 10.1016/ S0193-953X(05)70283-5

9. Rush AJ, Kraemer HC, Sackeim HA, Fava M, Trivedi MH, Frank E, et al. Report by the ACNP Task Force on response and remission in major depressive disorder. Neuropsychopharmacology (2006) 31(9):1841-53. doi: 10.1038/sj.npp.1301131

10. Fekadu A, Rane LJ, Wooderson SC, Markopoulou K, Poon L, Cleare AJ. Prediction of longer-term outcome of treatment-resistant depression in tertiary care. Br J Psychiatry (2012) 201(5):369-75. doi: 10.1192/bjp.bp.111.102665

11. Fekadu A, Wooderson SC, Markopoulo K, Donaldson C, Papadopoulos A, Cleare AJ. What happens to patients with treatment-resistant depression? A systematic review of medium to long term outcome studies. J Affect Disord (2009) 116(1-2):4-11. doi: 10.1016/j.jad.2008.10.014

12. Bennabi D, Aouizerate B, El-Hage W, Doumy O, Moliere F, Courtet P, et al. Risk factors for treatment resistance in unipolar depression: a systematic review. J Affect Disord (2015) 171:137-41. doi: 10.1016/j.jad.2014.09.020

13. Nierenberg AA. Predictors of response to antidepressants general principles and clinical implications. Psychiatr Clin North Am (2003) 26(2):345-52, viii. doi: 10.1016/S0193-953X(02)00105-3

14. Chavez-Castillo M, Nunez V, Nava M, Ortega A, Rojas M, Bermudez V, et al. Depression as a Neuroendocrine Disorder: Emerging Neuropsychopharmacological Approaches beyond Monoamines. Adv Pharmacol Sci (2019) 2019:7943481. doi: $10.1155 / 2019 / 7943481$

15. Pariante CM, Lightman SL. The HPA axis in major depression: classical theories and new developments. Trends Neurosci (2008) 31(9):464-8. doi: 10.1016/j.tins.2008.06.006

16. Holsboer F. The corticosteroid receptor hypothesis of depression. Neuropsychopharmacology (2000) 23(5):477-501. doi: 10.1016/S0893-133X (00)00159-7

17. Michelson D, Gold PW. Pathophysiologic and somatic investigations of hypothalamic-pituitary-adrenal axis activation in patients with depression. Ann N Y Acad Sci (1998) 840:717-22. doi: 10.1111/j.1749-6632.1998. tb09610.x

18. Stetler C, Miller GE. Depression and hypothalamic-pituitary-adrenal activation: a quantitative summary of four decades of research. Psychosom Med (2011) 73(2):114-26. doi: 10.1097/PSY.0b013e31820ad12b

19. Tichomirowa MA, Keck ME, Schneider HJ, Paez-Pereda M, Renner U, Holsboer F, et al. Endocrine disturbances in depression. J Endocrinol Invest (2005) 28(1):89-99. doi: 10.1007/BF03345535
20. Heuser I. Anna-Monika-Prize paper. The hypothalamic-pituitary-adrenal system in depression. Pharmacopsychiatry (1998) 31(1):10-3. doi: 10.1055/s2007-979288

21. Holsboer F, Barden N. Antidepressants and hypothalamic-pituitaryadrenocortical regulation. Endocr Rev (1996) 17(2):187-205. doi: 10.1210/ edrv-17-2-187

22. Heuser IJ, Schweiger U, Gotthardt U, Schmider J, Lammers CH, Dettling M, et al. Pituitary-adrenal-system regulation and psychopathology during amitriptyline treatment in elderly depressed patients and normal comparison subjects. Am J Psychiatry (1996) 153(1):93-9. doi: 10.1176/ ajp.153.1.93

23. Ising M, Horstmann S, Kloiber S, Lucae S, Binder EB, Kern N, et al. Combined dexamethasone/corticotropin releasing hormone test predicts treatment response in major depression - a potential biomarker? Bio Psychiatry (2007) 62(1):47-54. doi: 10.1016/j.biopsych.2006.07.039

24. Fischer S, Macare C, Cleare AJ. Hypothalamic-pituitary-adrenal (HPA) axis functioning as predictor of antidepressant response-Meta-analysis. Neurosci Biobehav Rev (2017) 83:200-11. doi: 10.1016/j.neubiorev.2017.10.012

25. Schule C, Baghai TC, Eser D, Hafner S, Born C, Herrmann S, et al. The combined dexamethasone/CRH Test (DEX/CRH test) and prediction of acute treatment response in major depression. PloS One (2009) 4(1):e4324. doi: 10.1371/journal.pone.0004324

26. Ribeiro SC, Tandon R, Grunhaus L, Greden JF. The DST as a predictor of outcome in depression: a meta-analysis. Am J Psychiatry (1993) 150 (11):1618-29. doi: 10.1176/ajp.150.11.1618

27. Perlman K, Benrimoh D, Israel S, Rollins C, Browna E, Tunteng JF, et al. A systematic meta-review of predictors of antidepressant treatment outcome in major depressive disorder. J Affect Disord (2019) 243:503-15. doi: 10.1016/ j.jad.2018.09.067

28. Rutigliano G, Rocchetti M, Paloyelis Y, Gilleen J, Sardella A, Cappucciati M, et al. Peripheral oxytocin and vasopressin: Biomarkers of psychiatric disorders? A comprehensive systematic review and preliminary meta-analysis. Psychiatry Res (2016) 241:207-20. doi: 10.1016/j.psychres.2016.04.117

29. Robertson GL. The regulation of vasopressin function in health and disease. Recent Prog Horm Res (1976) 33:333-85. doi: 10.1016/B978-0-12-5711333.50015-5

30. Morgenthaler NG, Struck J, Jochberger S, Dunser MW. Copeptin: clinical use of a new biomarker. Trends Endocrinol Metab (2008) 19(2):43-9. doi: 10.1016/j.tem.2007.11.001

31. Morgenthaler NG, Struck J, Alonso C, Bergmann A. Assay for the measurement of copeptin, a stable peptide derived from the precursor of vasopressin. Clin Chem (2006) 52(1):112-9. doi: 10.1373/clinchem.2005.060038

32. Bolignano D, Cabassi A, Fiaccadori E, Ghigo E, Pasquali R, Peracino A, et al. Copeptin (CTproAVP), a new tool for understanding the role of vasopressin in pathophysiology. Clin Chem Lab Med (2014) 52(10):1447-56. doi: 10.1515/cclm-2014-0379

33. Roussel R, Fezeu L, Marre M, Velho G, Fumeron F, Jungers P, et al. Comparison between copeptin and vasopressin in a population from the community and in people with chronic kidney disease. J Clin Endocrinol Metab (2014) 99(12):4656-63. doi: 10.1210/jc.2014-2295

34. Christ-Crain M, Fenske W. Copeptin in the diagnosis of vasopressindependent disorders of fluid homeostasis. Nat Rev Endocrinol (2016) 12 (3):168-76. doi: 10.1038/nrendo.2015.224

35. Zhang P, Wu X, Li G, Sun H, Shi J. Prognostic role of copeptin with all-cause mortality after heart failure: a systematic review and meta-analysis. Ther Clin Risk Manag (2017) 13:49-58. doi: 10.2147/TCRM.S124689

36. Xu Q, Tian Y, Peng H, Li H. Copeptin as a biomarker for prediction of prognosis of acute ischemic stroke and transient ischemic attack: a metaanalysis. Hypertens Res (2017) 40(5):465-71. doi: 10.1038/hr.2016.165

37. Katan M, Christ-Crain M. The stress hormone copeptin: a new prognostic biomarker in acute illness. Swiss Med Wkly (2010) 140:w13101. doi: 10.4414/ smw.2010.13101

38. Koch A, Yagmur E, Hoss A, Buendgens L, Herbers U, Weiskirchen R, et al. Clinical relevance of copeptin plasma levels as a biomarker of disease severity and mortality in critically ill patients. J Clin Lab Anal (2018) 32 (9):e22614. doi: 10.1002/jcla.22614

39. Demiralay C, Agorastos A, Yassouridis A, Jahn H, Wiedemann K, Kellner M. Copeptin - A potential endocrine surrogate marker of CCK-4-induced panic 
symptoms? Psychoneuroendocrinology (2017) 76:14-8. doi: 10.1016/ j.psyneuen.2016.11.006

40. Keck ME. Corticotropin-releasing factor, vasopressin and receptor systems in depression and anxiety. Amino Acids (2006) 31(3):241-50. doi: 10.1007/ s00726-006-0333-y

41. Kennedy SH, Lam RW, McIntyre RS, Tourjman SV, Bhat V, Blier P, et al. Canadian Network for Mood and Anxiety Treatments (CANMAT) 2016 Clinical Guidelines for the Management of Adults with Major Depressive Disorder: Section 3. Pharmacological Treatments. Can J Psychiatry (2016) 61 (9):540-60. doi: 10.1177/0706743716659417

42. National Institute for Health and Care Excellence. Depression in adults: recognition and management. Clin Guideline [CG90] (2009). [updated Apr 2018]: London.

43. DGPPN B. KBV, AWMF, S3-Leitlinie/Nationale VersorgungsLeitlinie Unipolare Depression - Langfassung. 2015.

44. Fiad TM, Kirby JM, Cunningham SK, McKenna TJ. The overnight singledose metyrapone test is a simple and reliable index of the hypothalamicpituitary-adrenal axis. Clin Endocrinol (Oxf) (1994) 40(5):603-9. doi: 10.1111/j.1365-2265.1994.tb03011.x

45. Avgerinos PC, Nieman LK, Oldfield EH, Cutler GBJr. A comparison of the overnight and the standard metyrapone test for the differential diagnosis of adrenocorticotrophin-dependent Cushing's syndrome. Clin Endocrinol (Oxf) (1996) 45(4):483-91. doi: 10.1046/j.1365-2265.1996.8170827.x

46. Gwirtsman H, Gerner RH, Sternbach H. The overnight dexamethasone suppression test: clinical and theoretical review. J Clin Psychiatry (1982) 43 (8):321-7.

47. Cole MA, Kim PJ, Kalman BA, Spencer RL. Dexamethasone suppression of corticosteroid secretion: evaluation of the site of action by receptor measures and functional studies. Psychoneuroendocrinology (2000) 25(2):151-67. doi: 10.1016/S0306-4530(99)00045-1

48. Drieling T, Scharer LO, Langosch JM. The Inventory of Depressive Symptomatology: German translation and psychometric validation. Int $J$ Methods Psychiatr Res (2007) 16(4):230-6. doi: 10.1002/mpr.226

49. Helmreich I, Wagner S, Mergl R, Allgaier AK, Hautzinger M, Henkel V, et al. The Inventory Of Depressive Symptomatology (IDS-C(28)) is more sensitive to changes in depressive symptomatology than the Hamilton Depression Rating Scale (HAMD(17)) in patients with mild major, minor or subsyndromal depression. Eur Arch Psychiatry Clin Neurosci (2011) 261 (5):357-67. doi: 10.1007/s00406-010-0175-1

50. Rush AJ, Gullion CM, Basco MR, Jarrett RB, Trivedi MH. The Inventory of Depressive Symptomatology (IDS): psychometric properties. Psychol Med (1996) 26(3):477-86. doi: 10.1017/S0033291700035558

51. Trivedi MH, Rush AJ, Crismon ML, Kashner TM, Toprac MG, Carmody TJ, et al. Clinical results for patients with major depressive disorder in the Texas Medication Algorithm Project. Arch Gen Psychiatry (2004) 61(7):669-80. doi: 10.1001/archpsyc.61.7.669

52. Rush AJ, Carmody T, Reimitz P-E. The inventory of depressive symptomatology (IDS): clinician (IDS-C) and self-report (IDS-SR) ratings of depressive symptoms. Int J Methods Psychiatr Res (2006) 9(2):45-59. doi: $10.1002 / \mathrm{mpr} .79$

53. Bernstein DP, Fink L. Childhood trauma questionnaire: A retrospective selfreport manual. San Antonio, TX: The Psychological Corporation (1998).

54. Buysse DJ, Reynolds CF3rd, Monk TH, Berman SR, Kupfer DJ. The Pittsburgh Sleep Quality Index: a new instrument for psychiatric practice and research. Psychiatry Res (1989) 28(2):193-213. doi: 10.1016/0165-1781 (89)90047-4

55. Lingjaerde O, Ahlfors UG, Bech P, Dencker SJ, Elgen K. The UKU side effect rating scale. A new comprehensive rating scale for psychotropic drugs and a cross-sectional study of side effects in neuroleptic-treated patients. Acta Psychiatr Scand Suppl (1987) 334:1-100. doi: 10.1111/j.1600-0447.1987.tb10566.x

56. Benjamini $Y$, Hochberg J. Controlling the False Discovery Rate: A Practical and Powerful Approach to Multiple Testing. J R Stat Soc S B (1995) 57 (1):289-300. doi: 10.1111/j.2517-6161.1995.tb02031.x

57. Agorastos A, Boel JA, Heppner PS, Hager T, Moeller-Bertram T, Haji U, et al. Diminished vagal activity and blunted diurnal variation of heart rate dynamics in posttraumatic stress disorder. Stress (2013) 16(3):300-10. doi: $10.3109 / 10253890.2012 .751369$
58. Agorastos A, Kellner M, Stiedl O, Muhtz C, Becktepe JS, Wiedemann K, et al. The 5-HTTLPR genotype modulates heart rate variability and its adjustment by pharmacological panic challenge in healthy men. J Psychiatr Res (2014) 50:51-8. doi: 10.1016/j.jpsychires.2013.11.013

59. Agorastos A, Demiralay C, Stiedl O, Muhtz C, Wiedemann K, Kellner M. Metabotropic glutamate $2 / 3$ receptor agonism facilitates autonomic recovery after pharmacological panic challenge in healthy humans. Int Clin Psychopharmacol (2016) 31(3):176-8. doi: 10.1097/YIC.0000000000000117

60. Agorastos A, Kellner M, Stiedl O, Muhtz C, Wiedemann K, Demiralay C. Blunted autonomic reactivity to pharmacological panic challenge under long-term escitalopram treatment in healthy men. Int $J$ Neuropsychopharmacol (2015) 18(5). doi: 10.1093/ijnp/pyu053

61. Agorastos A, Heinig A, Stiedl O, Hager T, Sommer A, Muller JC, et al. Vagal effects of endocrine HPA axis challenges on resting autonomic activity assessed by heart rate variability measures in healthy humans. Psychoneuroendocrinology (2019) 102:196-203. doi: 10.1016/ j.psyneuen.2018.12.017

62. Verhoeven KJF, Simonsen KL, McIntyre LM. Implementing false discovery rate control: increasing your power. Oikos (2005) 108(3):643-7. doi: 10.1111/j.0030-1299.2005.13727.x

63. Urwyler SA, Schuetz P, Sailer C, Christ-Crain M. Copeptin as a stress marker prior and after a written examination-the CoEXAM study. Stress (2015) 18 (1):134-7. doi: 10.3109/10253890.2014.993966

64. Spanakis EK, Wand GS, Ji N, Golden SH. Association of HPA axis hormones with copeptin after psychological stress differs by sex. Psychoneuroendocrinology (2016) 63:254-61. doi: 10.1016/j.psyneuen.2015.10.009

65. Siegenthaler J, Walti C, Urwyler SA, Schuetz P, Christ-Crain M. Copeptin concentrations during psychological stress: the PsyCo study. Eur J Endocrinol (2014) 171(6):737-42. doi: 10.1530/EJE-14-0405

66. Katan M, Morgenthaler N, Widmer I, Puder JJ, Konig C, Muller B, et al. Copeptin, a stable peptide derived from the vasopressin precursor, correlates with the individual stress level. Neuro Endocrinol Lett (2008) 29(3):341-6.

67. Lewandowski KC, Lewinski A, Skowronska-Jozwiak E, Malicka K, Horzelski W, Brabant G. Copeptin as a marker of an altered CRH axis in pituitary disease. Endocrine (2017) 57(3):474-80. doi: 10.1007/s12020-017-1366-6

68. Bae YJ, Reinelt J, Netto J, Uhlig M, Willenberg A, Ceglarek U, et al. Salivary cortisone, as a biomarker for psychosocial stress, is associated with state anxiety and heart rate. Psychoneuroendocrinology (2019) 101:35-41. doi: 10.1016/j.psyneuen.2018.10.015

69. Schinke C, Hesse S, Rullmann M, Becker GA, Luthardt J, Zientek F, et al. Central noradrenaline transporter availability is linked with HPA axis responsiveness and copeptin in human obesity and non-obese controls. Stress (2019) 22(1):93-102. doi: 10.1080/10253890.2018.1511698

70. Fuss J, Claro L, Ising M, Biedermann SV, Wiedemann K, Stalla GK, et al. Does sex hormone treatment reverse the sex-dependent stress regulation? A longitudinal study on hypothalamus-pituitary-adrenal (HPA) axis activity in transgender individuals. Psychoneuroendocrinology (2019) 104:228-37. doi: 10.1016/j.psyneuen.2019.02.023

71. Krogh J, Gotze JP, Jorgensen MB, Kristensen LO, Kistorp C, Nordentoft M. Copeptin during rest and exercise in major depression. J Affect Disord (2013) 151(1):284-90. doi: 10.1016/j.jad.2013.06.007

72. Morales-Medina JC, Witchey SK, Caldwell HK. The Role of Vasopressin in Anxiety and Depression in Melatonin. In: López-Muñoz F, Srinivasan V, de Berardis D, Álamo C, Kato TA., editors. Neuroprotective Agents and Antidepressant Therapy. New Delhi: Springer (2016). p. 667-85.

73. Aguilera G, Subburaju S, Young S, Chen J. The parvocellular vasopressinergic system and responsiveness of the hypothalamic pituitary adrenal axis during chronic stress. Prog Brain Res (2008) 170:29-39. doi 10.1016/S0079-6123(08)00403-2

74. Aguilera G, Rabadan-Diehl C. Vasopressinergic regulation of the hypothalamic-pituitary-adrenal axis: implications for stress adaptation. Regul Pept (2000) 96(1-2):23-9. doi: 10.1016/S0167-0115(00)00196-8

75. Landgraf $R$. The involvement of the vasopressin system in stress-related disorders. CNS Neurol Disord Drug Targets (2006) 5(2):167-79. doi: 10.2174/ 187152706776359664

76. Gold PW, Goodwin FK, Reus VI. Vasopressin in affective illness. Lancet (1978) 1(8076):1233-6. doi: 10.1016/S0140-6736(78)92467-4 
77. Stemmelin J, Lukovic L, Salome N, Griebel G. Evidence that the lateral septum is involved in the antidepressant-like effects of the vasopressin V1b receptor antagonist, SSR149415. Neuropsychopharmacology (2005) 30 (1):35-42. doi: 10.1038/sj.npp.1300562

78. Lolait SJ, O'Carroll AM, Brownstein MJ. Molecular biology of vasopressin receptors. Ann N Y Acad Sci (1995) 771:273-92. doi: 10.1111/j.17496632.1995.tb44688.x

79. Lolait SJ, O'Carroll AM, Mahan LC, Felder CC, Button DC, Young WS3rd, et al. Extrapituitary expression of the rat V1b vasopressin receptor gene. Proc Natl Acad Sci U S A (1995) 92(15):6783-7. doi: 10.1073/pnas.92.15.6783

80. Lolait SJ, Stewart LQ, Jessop DS, Young WS3rd, O'Carroll AM. The hypothalamic-pituitary-adrenal axis response to stress in mice lacking functional vasopressin V1b receptors. Endocrinology (2007) 148(2):84956. doi: 10.1210/en.2006-1309

81. Aguilera G, Rabadan-Diehl C. Regulation of vasopressin V1b receptors in the anterior pituitary gland of the rat. Exp Physiol (2000) 85. Spec No: 19S26S. doi: 10.1111/j.1469-445X.2000.tb00004.x

82. O'Keane V, Frodl T, Dinan TG. A review of Atypical depression in relation to the course of depression and changes in HPA axis organization. Psychoneuroendocrinology (2012) 37(10):1589-99. doi: 10.1016/ j.psyneuen.2012.03.009

83. Murgatroyd C, Wigger A, Frank E, Singewald N, Bunck M, Holsboer F, et al. Impaired repression at a vasopressin promoter polymorphism underlies overexpression of vasopressin in a rat model of trait anxiety. J Neurosci (2004) 24(35):7762-70. doi: 10.1523/JNEUROSCI.1614-04.2004

84. Purba JS, Hoogendijk WJ, Hofman MA, Swaab DF. Increased number of vasopressin- and oxytocin-expressing neurons in the paraventricular nucleus of the hypothalamus in depression. Arch Gen Psychiatry (1996) 53 (2):137-43. doi: 10.1001/archpsyc.1996.01830020055007

85. Meynen G, Unmehopa UA, van Heerikhuize JJ, Hofman MA, Swaab DF, Hoogendijk WJ. Increased arginine vasopressin mRNA expression in the human hypothalamus in depression: A preliminary report. Biol Psychiatry (2006) 60(8):892-5. doi: 10.1016/j.biopsych.2005.12.010

86. van Londen L, Goekoop JG, van Kempen GM, Frankhuijzen-Sierevogel AC, Wiegant VM, van der Velde EA, et al. Plasma levels of arginine vasopressin elevated in patients with major depression. Neuropsychopharmacology (1997) 17(4):284-92. doi: 10.1016/S0893-133X(97)00054-7

87. Goekoop J, de Winter R, Wolterbeek R, Wiegant V. Support for two increased vasopressinergic activities in depression at large and the differential effect of antidepressant treatment. J Psychopharmacol (2011) 25 (10):1304-12. doi: 10.1177/0269881110372549

88. Goekoop JG, de Winter RP, de Rijk R, Zwinderman KH, FrankhuijzenSierevogel A, Wiegant VM. Depression with above-normal plasma vasopressin: validation by relations with family history of depression and mixed anxiety and retardation. Psychiatry Res (2006) 141(2):201-11. doi: 10.1016/j.psychres.2005.09.003

89. Goekoop JG, de Winter RF, Wolterbeek R, van Kempen GM, Wiegant VM. Evidence of vasopressinergic-noradrenergic mechanisms in depression with above-normal plasma vasopressin concentration with and without psychotic features. J Psychopharmacol (2011) 25(3):345-52. doi: 10.1177/0269881109349839

90. de Winter RF, van Hemert AM, DeRijk RH, Zwinderman KH, FrankhuijzenSierevogel AC, Wiegant VM, et al. Anxious-retarded depression: relation with plasma vasopressin and cortisol. Neuropsychopharmacology (2003) 28 (1):140-7. doi: 10.1038/sj.npp.1300002

91. Muller MB, Landgraf R, Keck ME. Vasopressin, major depression, and hypothalamic-pituitary-adrenocortical desensitization. Biol Psychiatry (2000) 48(4):330-3. doi: 10.1016/S0006-3223(00)00886-6

92. Zelena D. Vasopressin in health and disease with a focus on affective disorders. Cent Nerv Syst Agents Med Chem (2012) 12(4):286-303. doi: 10.2174/187152412803760609

93. Poretti MB, Sawant RS, Rask-Andersen M, de Cuneo MF, Schioth HB, Perez MF, et al. Reduced vasopressin receptors activation mediates the anti-depressant effects of fluoxetine and venlafaxine in bulbectomy model of depression. Psychopharmacol (Berl) (2016) 233(6):1077-86. doi: 10.1007/s00213-015-4187-4

94. van Londen L, Kerkhof GA, van den Berg F, Goekoop JG, Zwinderman KH, Frankhuijzen-Sierevogel AC, et al. Plasma arginine vasopressin and motor activity in major depression. Biol Psychiatry (1998) 43(3):196-204. doi: 10.1016/S0006-3223(97)80433-7

95. Ionescu DF, Papakostas GI. Experimental medication treatment approaches for depression. Transl Psychiatry (2017) 7(3):e1068. doi: 10.1038/tp.2017.33

96. Griebel G, Beeske S, Stahl SM. The vasopressin V(1b) receptor antagonist SSR149415 in the treatment of major depressive and generalized anxiety disorders: results from 4 randomized, double-blind, placebo-controlled studies. J Clin Psychiatry (2012) 73(11):1403-11. doi: 10.4088/ JCP.12m07804

97. Griebel G, Simiand J, Serradeil-Le Gal C, Wagnon J, Pascal M, Scatton B, et al. Anxiolytic- and antidepressant-like effects of the non-peptide vasopressin V1b receptor antagonist, SSR149415, suggest an innovative approach for the treatment of stress-related disorders. Proc Natl Acad Sci U S A (2002) 99(9):6370-5. doi: 10.1073/pnas.092012099

98. Alonso R, Griebel G, Pavone G, Stemmelin J, Le Fur G, Soubrie P. Blockade of $\mathrm{CRF}(1)$ or $\mathrm{V}(1 \mathrm{~b})$ receptors reverses stress-induced suppression of neurogenesis in a mouse model of depression. Mol Psychiatry (2004) 9 (3):278-86, 224. doi: 10.1038/sj.mp.4001464

99. Louis C, Cohen C, Depoortere R, Griebel G. Antidepressant-like effects of the corticotropin-releasing factor 1 receptor antagonist, SSR125543, and the vasopressin 1b receptor antagonist, SSR149415, in a DRL-72 s schedule in the rat. Neuropsychopharmacology (2006) 31(10):2180-7. doi: 10.1038/ sj.npp.1301036

100. Goncharova ND, Chigarova OA, Oganyan TE. Effect of Vasopressin V1b Receptor Blockade on Activity of the Hypothalamic-Pituitary-Adrenal Axis in Old Monkeys with Depression-Like and Anxious Behavior Subjected to Stress or Injected with Vasopressin. Bull Exp Biol Med (2018) 166(1):86-91. doi: 10.1007/s10517-018-4294-4

101. Stewart LQ, Roper JA, Young WS3rd, O'Carroll AM, Lolait SJ. The role of the arginine vasopressin Avplb receptor in the acute neuroendocrine action of antidepressants. Psychoneuroendocrinology (2008) 33(4):405-15. doi: 10.1016/j.psyneuen.2007.12.009

102. Gili M, Roca M, Armengol S, Asensio D, Garcia-Campayo J, Parker G. Clinical patterns and treatment outcome in patients with melancholic, atypical and non-melancholic depressions. PloS One (2012) 7(10):e48200. doi: 10.1371/journal.pone.0048200

103. Otte C, Wingenfeld K, Kuehl LK, Kaczmarczyk M, Richter S, Quante A, et al. Mineralocorticoid receptor stimulation improves cognitive function and decreases cortisol secretion in depressed patients and healthy individuals. Neuropsychopharmacology (2015) 40(2):386-93. doi: 10.1038/npp.2014.181

104. Kellner M, Muhtz C, Weinas A, Curic S, Yassouridis A, Wiedemann K. Impact of physical or sexual childhood abuse on plasma DHEA, DHEA-S and cortisol in a low-dose dexamethasone suppression test and on cardiovascular risk parameters in adult patients with major depression or anxiety disorders. Psychiatry Res (2018) 270:744-8. doi: 10.1016/ j.psychres.2018.10.068

105. Otte C, Hinkelmann K, Moritz S, Yassouridis A, Jahn H, Wiedemann K, et al. Modulation of the mineralocorticoid receptor as add-on treatment in depression: a randomized, double-blind, placebo-controlled proof-ofconcept study. J Psychiatr Res (2010) 44(6):339-46. doi: 10.1016/ j.jpsychires.2009.10.006

106. Strawbridge R, Young AH, Cleare AJ. Biomarkers for depression: recent insights, current challenges and future prospects. Neuropsychiatr Dis Treat (2017) 13:1245-62. doi: 10.2147/NDT.S114542

Conflict of Interest: The authors declare that the research was conducted in the absence of any commercial or financial relationships that could be construed as a potential conflict of interest.

Copyright (c) 2020 Agorastos, Sommer, Heinig, Wiedemann and Demiralay. This is an open-access article distributed under the terms of the Creative Commons Attribution License (CC BY). The use, distribution or reproduction in other forums is permitted, provided the original author(s) and the copyright owner(s) are credited and that the original publication in this journal is cited, in accordance with accepted academic practice. No use, distribution or reproduction is permitted which does not comply with these terms. 